\title{
Long periodicals in the position of permanent GNSS stations
}

\author{
Victoria Ivanova $^{1 *}$, and Sergey Tyurin ${ }^{1}$ \\ ${ }^{1}$ Department of Cartography and Geoinformatics, Institute of Earth Sciences, Saint Petersburg State University, St. Petersburg, Russia
}

\begin{abstract}
The relevance of the study of the movements of base reference stations is determined by the task of improving the accuracy and reliability of the results of geodetic monitoring carried out using GNSS technologies. The paper presents the results of an analysis of the position of five permanent GNSS stations located in St. Petersburg for 2013-2020. Data processing by the method of precise positioning was performed using the online service CSRS-PPP. The time series were processed using the "Caterpillar"-SSA algorithm implemented in the MathCAD software package. The main attention is paid to the identification of periodic components in the movement of stations. The analysis of the series showed consistently identified periods of 3 and 12 months in the plane coordinates and 70 days and 12 months in altitude. The amplitudes of the periodicals were in the range from 1 to 10 millimeters. A trend was also identified, demonstrating a tendency for all stations to move to the northeast. The paper presents comparisons of the results obtained with previous studies.
\end{abstract}

\section{Introduction}

Currently, a wide range of geodetic works that require high-precision determination of time and location is carried out using GPS Technologies (Global Navigation Satellite System). The main difference between this technology and classical methods is the continuity of measurements. The main advantage of continuity is the ability to identify different periodicals (unlike classical methods, which do not allow conducting and measurements with the required frequency). Automation of the process, which minimizes gross errors, is another advantage of using GNSS technologies. In addition, the use of this method can significantly reduce the dependence of the work on weather conditions.

The current stage is characterized by the active development of geodetic monitoring using GNSS technologies. The main advantages, in particular, the continuity of measurements and automation, allows this method of geodetic monitoring to be widely used and applied in many industries, science and construction.

\section{Network of reference base stations in Saint Petersburg}

To analyze the long-period movements of the stations, data obtained from the network of reference stations of the Committee for Urban Planning and Architecture of St. Petersburg (http://ref.kgainfo.spb.ru/) were used. This network consists of continuously operating stations, the location of which is determined with high accuracy using GNSS technologies. Due to the fact that round-the-clock monitoring is continuously carried out at the stations, the stations are located in places where the effects of external factors are absent or minimized.

A reference station is a hardware and software complex that serves to perform measurements and determine the position. The station consists of a receiver, an antenna fixed in space, a power source and communication means. The points of the network were fixed by special centers on the roofs of buildings, if possible, on the capital wall. The creation of network was carried out in 2010-2013 according to a special project, which took into account the issues of the suitability of buildings for performing long-term measurements, the specifics of fixing the centers, placing the receiving equipment and the conditions for conducting observations with minimal external factors.

To determine the coordinates, three-day observations were used at base stations and points of International GNSS Service (SVTL, ZWE2, RIGA, JOEN, MOBN, MDVJ) in the period from 22.05.2013 to 24.05.2013. The principle of high uniform accuracy of the urban geodetic basis, which allows minimizing errors for the mutual position of pairs of points, was implemented by building a three-stage network:

- network of reference stations;

- wireframe network;

- satellite geodetic network of the 1st class.

The results were processed using modern computers capable of implementing multi-session processing options in 2 stages:

- free equalization was performed with fixing in the geocentric coordinate system;

\footnotetext{
${ }^{*}$ Corresponding author: ivanovavitani@mail.ru
} 
- by parallel transfer of the free network, the smallest residuals relative to International Service stations were achieved.

After processing, the residuals did not exceed 3 millimeters in plane coordinates and 7 millimeters in altitude. The coordinates were determined as rectangular spatial coordinates in the geocentric International Coordinate System ITRF 2008 for the epoch of 23.05.2013. To calculate geodetic coordinates and altitudes, the WGS-84 ellipsoid was used as a reference. The Precise Point Positioning method was used to control the results. The coordinates of the points were obtained relative to the IGS stations with an error of less than 1 centimeters.

The network of stations extends a high-precision coordinate space to the territory of the city and its surroundings, which is connected to the state coordinate system SK-95 through a wireframe network and the satellite geodetic network of the 1st class.

The network includes 10 base stations. Leica GR10 receivers with Leica AR25 antennas are installed at the points, which have 120 channels, are able to observe up to 60 satellites and support work with GPS, GLONASS and Galileo satellites. The network is managed by the St. Petersburg Center for Information Support of Urban Planning Activities.

\section{Data preparation and processing}

The initial data used hourly RINEX files for 2013-2020 from the GORN, KRON, KUP 2, LOM 2, SEST stations located in the Vasileostrovsky, Kronshtadtsky, Frunzensky, Petrodvortsovy and Kurortny districts of St. Petersburg. Using the Topcon Magnet Tools software, the source data was combined into five-day RINEX files for further processing by the PPP method.

Data processing by the PPP method was carried out using the online service CSRS-PPP. Before uploading to the service, the hourly files were imported into the Topcon Magnet Tools software and the five-day RINEX files (raw GPS+ data) of versions 2 and 3 were exported.

The files were uploaded to the service for processing in static mode. The parameters of the international coordinate system ITRF-08 were used as the reference system of the output data.

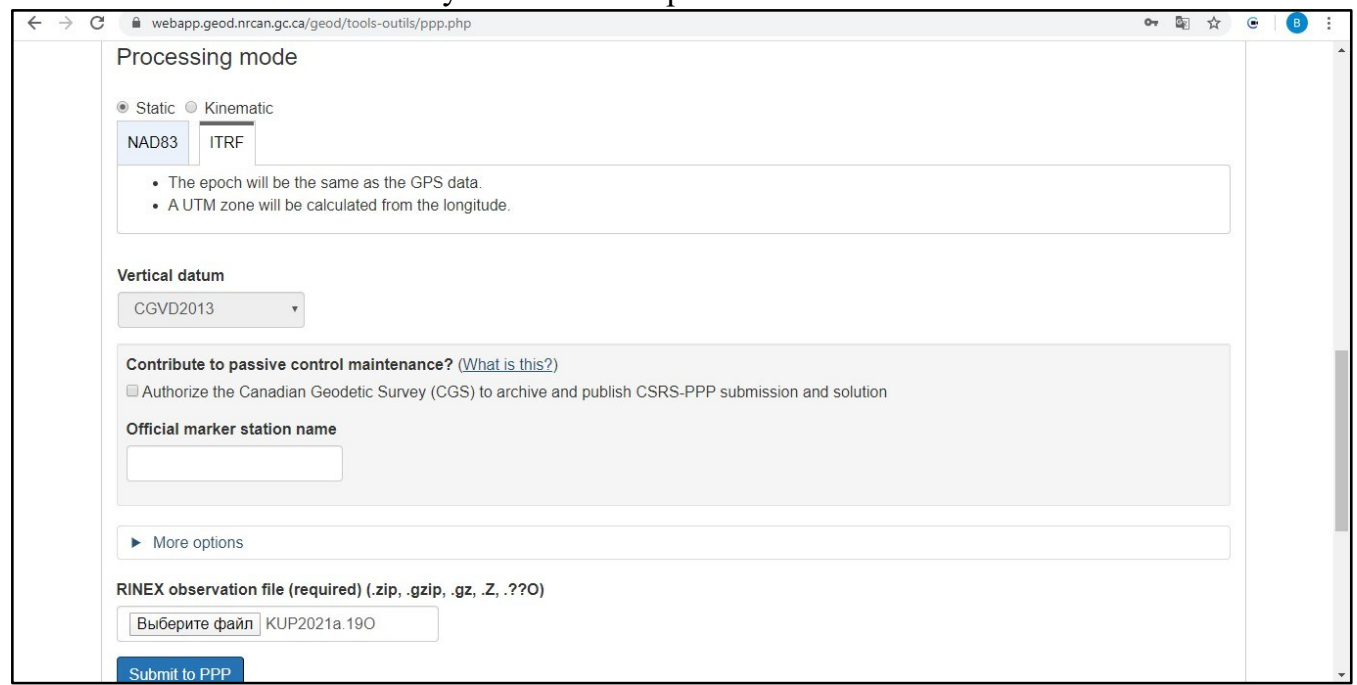

Fig. 1. Page view of the CSRS-PPP online service

According to the results of processing, the user receives the final absolute coordinates.

The report is an archive containing the following files:

- report in the form (. pdf). This file contains text and graphic information about the processing.

- a file of the format (. sum) containing the results and processing parameters in text format;

- a file of the format (.pos). The file contains location information for each processed epoch;

- a file of the format (.csv), a text file with a comma as a separator, containing information about the clock and location for each processed epoch;

- a file of the format (. tro) containing information about dry and wet zenith delays and the tropospheric gradient for each processed epoch;

- a file of the format (.clk) containing the receiver clock offset and the clock offset sigma (95\%) for each processed epoch;

- a file of the format (.txt) containing errors and warnings that occurred during the operation of the service.

The mean squared errors in the plan did not exceed $2 \mathrm{~mm}$, the altitude errors were in the range of 4-6 mm.

Based on the obtained coordinates, time series were compiled in Microsoft Excel software for further processing and analysis.

\section{Processing of time series using the "Caterpillar"-SSA method}

The result of processing satellite measurements is a time series. For further research, mathematical algorithms for time series analysis are used. In this study, the actively developing "Caterpillar" or SSA (Singular Spectrum Analysis) method 
was used to identify the trend and noise. This algorithm is being developed independently in Russia and in the UK. In Russia, the "Caterpillar"-SSA method is being studied at St. Petersburg State University by N. E. Golyandina and other scientists $[1,2]$.

The "Caterpillar"-SSA method is a convenient tool that is used in many branches of science and technology, including geodesy [3].

\subsection{The basic algorithm of the "Caterpillar"-SSA method}

According to the theory [1], the basic algorithm consists of the following stages:

- decomposition: embedding and singular value decomposition (SVD);

- recovery: eigentriple grouping and diagonal averaging.

All the formulas and concepts given below are based on the textbook by N. E. Golyandina [1].

Consider a real time series:

$$
F=\left(f_{0}, \ldots, f_{N-1}\right),
$$

$\mathrm{N}>2$ is the length of the series. This series is non-zero, i.e., there is at least one non-zero term of the series

Step 1. Embedding

At this stage, the time series is converted into a sequence of multidimensional vectors. To analyze the time series, the integer parameter $\mathrm{L}$ is selected - the length of the window, $1<\mathrm{L}<\mathrm{N}$. As a result, $\mathrm{K}=\mathrm{N}-\mathrm{L}+1$ embedding vectors with dimension $\mathrm{L}$ are formed:

$$
X_{i}=\left(f_{i-1}, \ldots, f_{i+L-2}\right)^{T},
$$

where $1 \leq i \leq K$. Then a trajectory matrix is formed, consisting of embedding vectors as columns:

$$
\begin{aligned}
X & =\left[X_{1}: \ldots: X_{K}\right], \\
X=\left(x_{i, j}\right)_{i, j=1}^{L, K}= & \left(\begin{array}{cccc}
f_{0} & f_{1} & \ldots & f_{K-1} \\
f_{1} & f_{2} & \ldots & f_{K} \\
\vdots & \vdots & \ddots & \vdots \\
f_{L-1} & f_{L} & \ldots & f_{N-1}
\end{array}\right) .
\end{aligned}
$$

This matrix is a Hankel matrix, i.e. it has equal elements on all diagonals perpendicular to the main one.

Step 2. SVD - Singular Value Decomposition.

At this step, the matrix $X$ is converted into the sum of elementary matrices.

Let $S=X X^{T}, \lambda_{1}, \ldots, \lambda_{L}$ - the eigenvalues of the matrix $\mathrm{S}$, taken in non-decreasing order. $U_{1}, \ldots, U_{L}$ is an orthonomized system of eigenvectors of the matrix $S$ corresponding to the eigenvalues.

Let $d=\max \left\{i: \lambda_{i}>0\right\}$. If we take $V_{i}=X^{T} U_{i} / \sqrt{\lambda_{i}}$, where $i=1, \ldots, d$, then the singular value decomposition of the matrix $\mathrm{X}$ will look like this:

$$
\begin{gathered}
X=X_{1}+\cdots+X_{d}, \\
X_{i}=\sqrt{\lambda_{i}} U_{i} V_{i}^{T}
\end{gathered}
$$

Each of the matrices $X_{i}$ is an elementary matrix. The collection $\left(\sqrt{\lambda_{i}}, U_{i}, V_{i}\right)$ will be called the ist eigentriple of the $\mathrm{SVD}, \sqrt{\lambda_{i}}$ is a singular value, $U_{i}, V_{i}$ are the eigenvectors and factor vectors, respectively (the left and right singular vectors of the matrix X).

Step 3. Eigentriple grouping.

After decomposition, the entire set of indices $\{1, \ldots, d\}$ is divided by the grouping procedure into $m$ disjoint subsets $I_{1}, \ldots, I_{m}$. If we take $I=\left\{i_{1}, \ldots, i_{p}\right\}$, then the matrix $X_{I}$ of group $I$ is calculated as follows:

$$
X_{1}=X_{i_{1}}+\cdots+X_{i_{p}}
$$

Matrices for $I=I_{1}, \ldots, I_{m}$ are calculated similarly. Thus, the decomposition can be written in a grouped form:

$$
X=X_{I_{1}}+\cdots+X_{I_{m}} \text {. }
$$

The eigentriple grouping step implies the identification of eigentriples with their grouping [1]. At this step, the main trend, periodicals and noise are determined [4].

Step 4. Diagonal averaging.

At this stage, new series of length $N$ are created based on the matrices of the grouped decomposition.

The matrix Y (a matrix of dimension $\mathrm{L} \times \mathrm{K}$ with elements $y_{i j}$, where $1 \leq i \leq L, 1 \leq j \leq K$ ) is converted to a series $g_{0}, \ldots, g_{N-1}$ by the formula: 


$$
g_{k}=\left\{\begin{array}{lr}
\frac{1}{k+1} \sum_{m=1}^{k+1} y_{m, k-m+2}^{*} & \text { для } 0 \leq k<L^{*}-1, \\
\frac{1}{L^{*}} \sum_{m=1}^{L^{*}} y_{m, k-m+2}^{*} & \text { для } L^{*}-1 \leq k<K^{*}, \\
\frac{1}{N-k} \sum_{m=k-K^{*}+2}^{N-K^{*}+1} y_{m, k-m+2}^{*} & \text { для } K^{*} \leq k<N,
\end{array}\right.
$$

where $L^{*}=\min (L, K), K^{*}=\max (L, K), N=L+K-1 ; y_{i j}^{*}=y_{i j}$, if $L<K$, else $y_{i j}^{*}=y_{j i}$.

Applying diagonal averaging to the resulting matrices $X_{I_{k}}$, we get the series

$$
\tilde{F}^{(k)}=\tilde{f}_{0}^{(k)}, \ldots, \tilde{f}_{N-1}^{(k)} \text {. }
$$

Thus, the initial series can be decomposed into the sum of $m$ series:

$$
f_{n}=\sum_{k=1}^{m} \tilde{f}_{n}^{(k)}
$$

\subsection{Implementation of the "Caterpillar"-SSA algorithm}

The "Caterpillar"-SSA algorithm was implemented in the MathCAD software package.

The program uses the built-in function to request a format file .txt, which contains the time series, then, using the vectors of the transformed centered series with the window length parameter L, the trajectory matrix is set. The length of the window $\mathrm{L}$ is set equal to half the length of the row. Below is a fragment of the data series after centering $(d r)$ and a fragment of the trajectory matrix $(X)$.

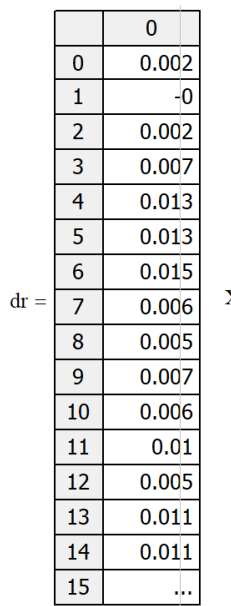

\begin{tabular}{|r|r|r|r|r|r|r|r|r|r|}
\hline & \multicolumn{1}{|c|}{0} & \multicolumn{1}{c|}{1} & \multicolumn{1}{c|}{2} & \multicolumn{1}{c|}{3} & \multicolumn{1}{c|}{4} & \multicolumn{1}{c|}{5} & \multicolumn{1}{c}{6} & \multicolumn{1}{c|}{7} & \multicolumn{1}{c|}{8} \\
\hline 0 & 0.002 & -0 & 0.002 & 0.007 & 0.013 & 0.013 & 0.015 & 0.006 & 0.005 \\
\hline 1 & -0 & 0.002 & 0.007 & 0.013 & 0.013 & 0.015 & 0.006 & 0.005 & 0.007 \\
\hline 2 & 0.002 & 0.007 & 0.013 & 0.013 & 0.015 & 0.006 & 0.005 & 0.007 & 0.006 \\
\hline 3 & 0.007 & 0.013 & 0.013 & 0.015 & 0.006 & 0.005 & 0.007 & 0.006 & 0.01 \\
\hline 4 & 0.013 & 0.013 & 0.015 & 0.006 & 0.005 & 0.007 & 0.006 & 0.01 & 0.005 \\
\hline 5 & 0.013 & 0.015 & 0.006 & 0.005 & 0.007 & 0.006 & 0.01 & 0.005 & 0.011 \\
\hline 6 & 0.015 & 0.006 & 0.005 & 0.007 & 0.006 & 0.01 & 0.005 & 0.011 & 0.011 \\
\hline 7 & 0.006 & 0.005 & 0.007 & 0.006 & 0.01 & 0.005 & 0.011 & 0.011 & 0.014 \\
\hline 8 & 0.005 & 0.007 & 0.006 & 0.01 & 0.005 & 0.011 & 0.011 & 0.014 & 0.01 \\
\hline 9 & 0.007 & 0.006 & 0.01 & 0.005 & 0.011 & 0.011 & 0.014 & 0.01 & 0.008 \\
\hline 10 & 0.006 & 0.01 & 0.005 & 0.011 & 0.011 & 0.014 & 0.01 & 0.008 & 0.016 \\
\hline 11 & 0.01 & 0.005 & 0.011 & 0.011 & 0.014 & 0.01 & 0.008 & 0.016 & 0.017 \\
\hline 12 & 0.005 & 0.011 & 0.011 & 0.014 & 0.01 & 0.008 & 0.016 & 0.017 & 0.017 \\
\hline 13 & 0.011 & 0.011 & 0.014 & 0.01 & 0.008 & 0.016 & 0.017 & 0.017 & 0.032 \\
\hline 14 & 0.011 & 0.014 & 0.01 & 0.008 & 0.016 & 0.017 & 0.017 & 0.032 & 0.032 \\
\hline 15 & 0.014 & 0.01 & 0.008 & 0.016 & 0.017 & 0.017 & 0.032 & 0.032 & $\ldots$ \\
\hline
\end{tabular}

Fig. 2. A fragment of the data series after centering and a fragment of the trajectory matrix

Then the vectors of the singular values $\lambda$ and the matrices of the eigenvectors and factor vectors $U, V$ are calculated. If the window length is equal to half of the series, the matrices will be the same. Then the components of the singular value decomposition are found. As a result, five matrices are formed. By averaging over anti-diagonals, five components are recovered.
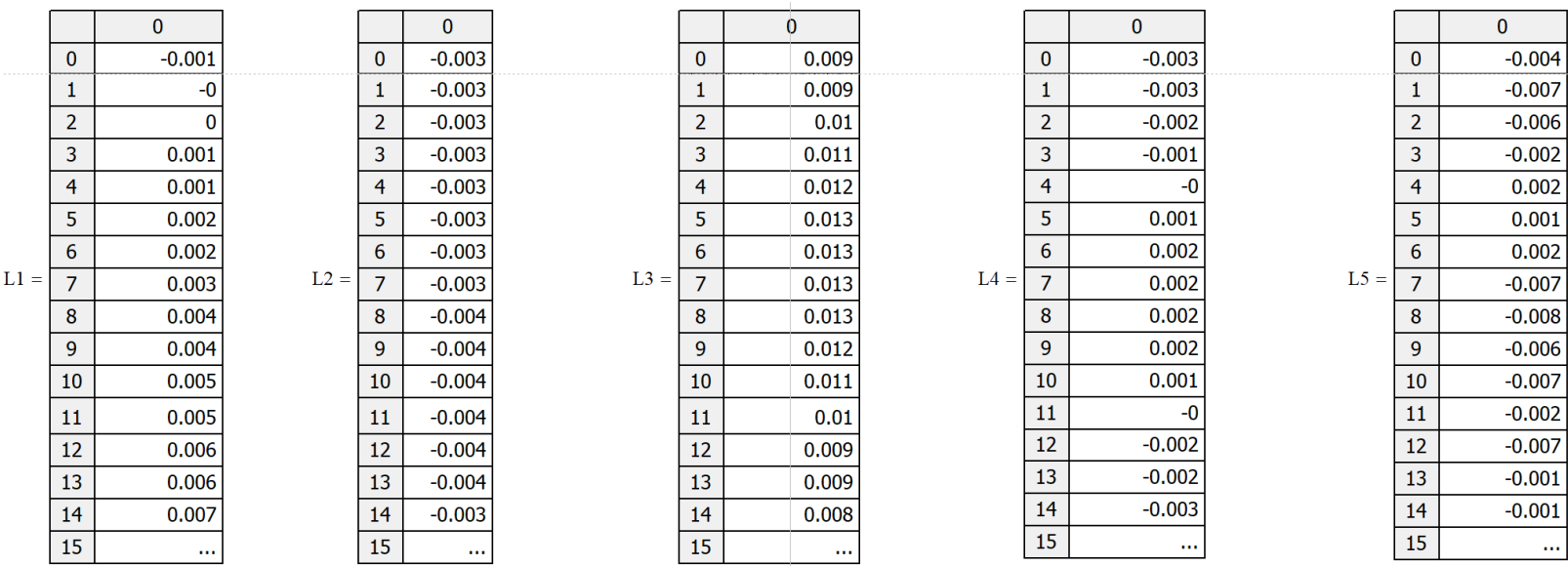

Fig. 3. The recovery of five components

The Figure 4 shows the view of these components. 


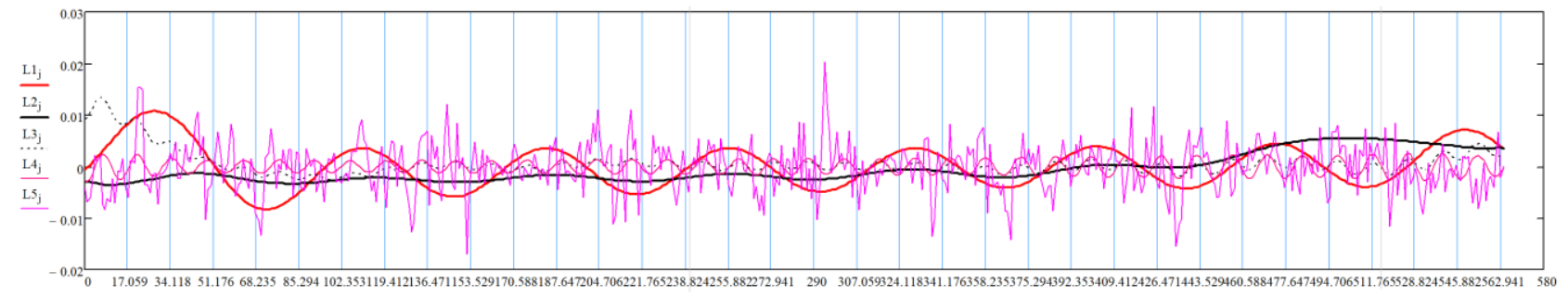

Fig. 4. The graph of components L1, L2, L3, L4, L5

The components L1, L2, L3 and L4 are periodic components, the component L5 is the residual noise. The central parts of the series have the greatest reliability due to the fact that the elements of the series are obtained by averaging over antidiagonals.

The graphs of the covariance matrices have a damped appearance, based on this, we can conclude that the noise is close to white. According to the work of Gorshkov V. L., the noise of satellite measurements is close to flicker noise or is intermediate between white and pink noise [5].

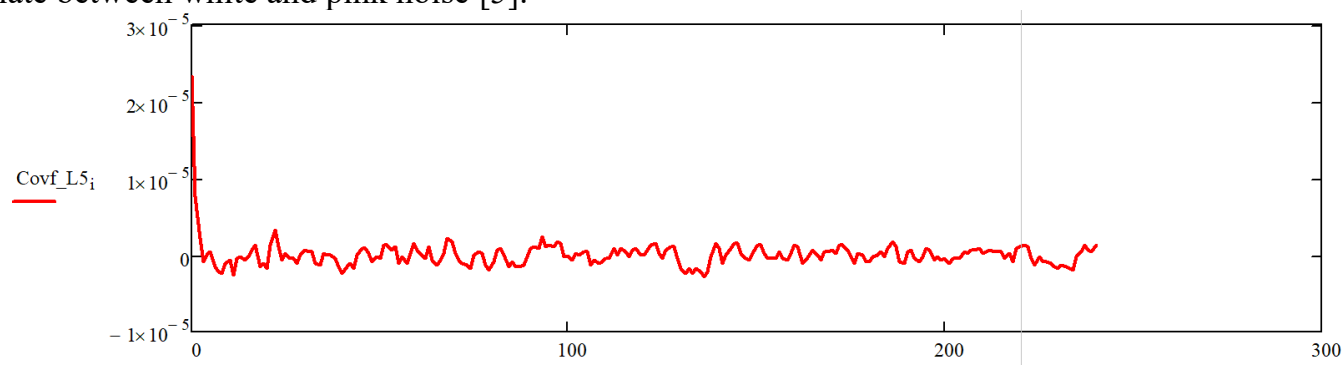

Fig. 5. The graph of covariance matrix.

The Figure 6 shows a noisy graph of the function.

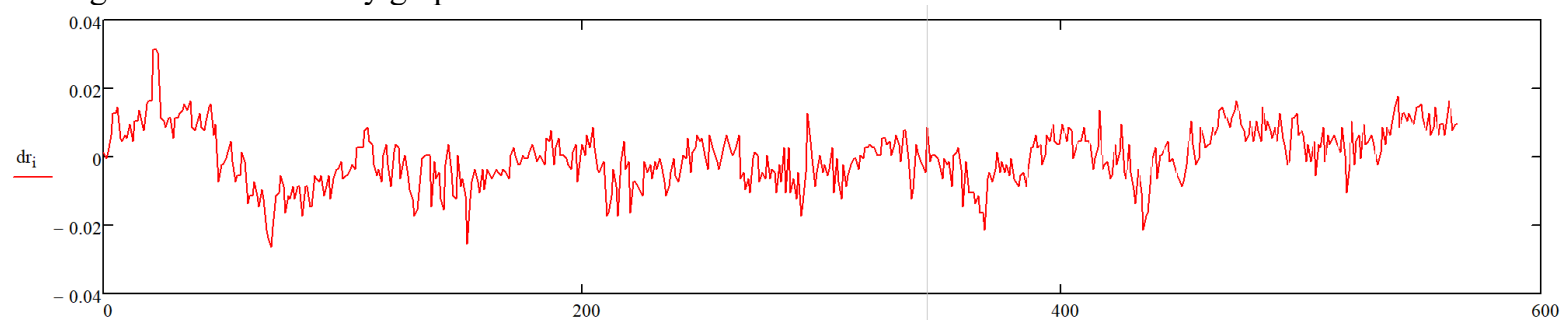

Fig. 6. The graph of a function with a noise component.

The "Caterpillar"-SSA method is a convenient tool for analyzing, predicting time series and dividing them into components. One of the advantages of the method is the absence of a strict need for information about the features, characteristics and structure of the series. However, the results obtained do not explain the causes of the components.

\section{Analysis of changes in the position of reference base stations}

According to the results of processing, various components of the series are identified, which can be divided into 3 groups: trend, periodic components and noise. If different components had the same or similar periods, then they were combined.

The graph shown in Figure 7 shows an example of decomposition into components for station movements in altitude.

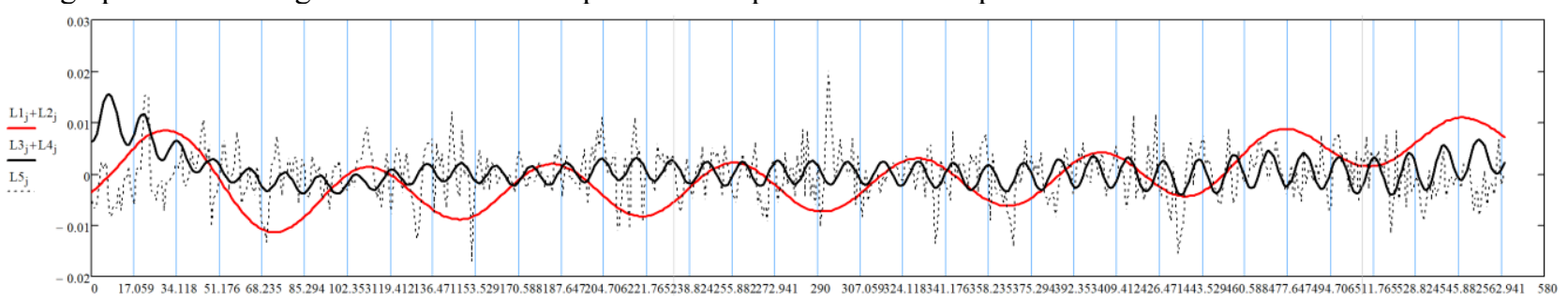

Fig. 7. The graph of the series components, the altitude, SEST station

The graph below shows the resulting trend in the movement of the station in the plane coordinates in the South-North direction. The same trends were obtained in the West-East direction. 


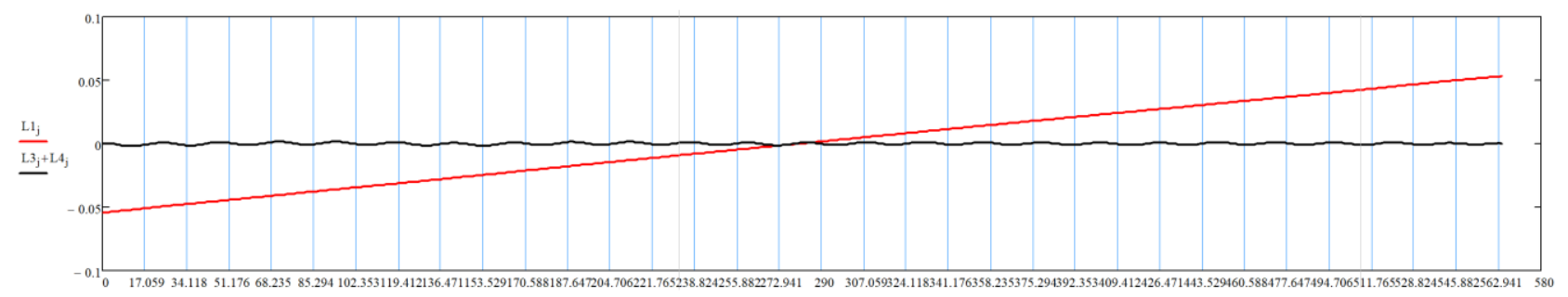

Fig. 8. The graph of components of a series of plane coordinates of the SEST station

The graph in Figure 9 shows the periodic components of a series of coordinates obtained after excluding the trend and noise.

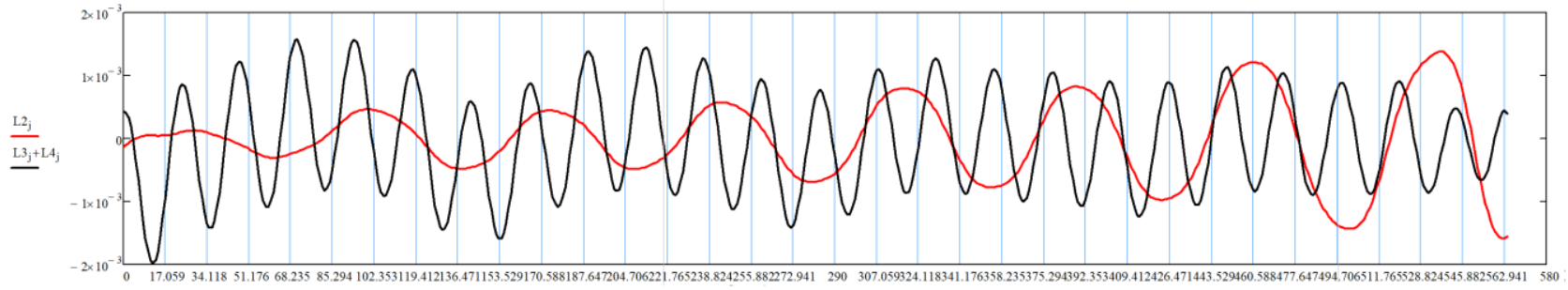

Fig. 9. The graph of periodic components of a series of plane coordinates of the SEST station

The table below shows the identified periodic components of the station movements in the plane coordinates and in altitude.

Table 1. Periodic movements of stations in plane coordinates and in altitude

\begin{tabular}{|c|c|c|c|c|c|}
\hline & GORN & KRON & KUP2 & LOM2 & SEST \\
\hline $\begin{array}{c}\text { The altitude } \\
\text { component }\end{array}$ & $\begin{array}{c}12 \text { months, } 70 \\
\text { days }\end{array}$ & $\begin{array}{c}12 \text { months, } 70 \\
\text { days }\end{array}$ & $\begin{array}{c}12 \text { months, } 70 \\
\text { days }\end{array}$ & $\begin{array}{c}12 \text { months, } 70 \\
\text { days }\end{array}$ & $\begin{array}{c}12 \text { months, } 70 \\
\text { days }\end{array}$ \\
\hline $\begin{array}{c}\text { The component } \\
\text { of the plane } \\
\text { coordinates, the } \\
\text { direction S-N }\end{array}$ & $\begin{array}{c}12 \text { months, } 3 \\
\text { months }\end{array}$ & $\begin{array}{c}12 \text { months, } 3 \\
\text { months }\end{array}$ & $\begin{array}{c}12 \text { months, } 3 \\
\text { months }\end{array}$ & $\begin{array}{c}12 \text { months, } 3 \\
\text { months }\end{array}$ & $\begin{array}{c}12 \text { months, } 3 \\
\text { months }\end{array}$ \\
\hline $\begin{array}{c}\text { The component } \\
\text { of the plane } \\
\text { coordinates, the } \\
\text { direction W-E }\end{array}$ & $\begin{array}{c}24 \text { months, } 3 \\
\text { months }\end{array}$ & $\begin{array}{c}12 \text { months, } 3 \\
\text { months }\end{array}$ & $\begin{array}{c}12 \text { months, } 3 \\
\text { months }\end{array}$ & $\begin{array}{c}21 \text { months, } 3 \\
\text { months }\end{array}$ & $\begin{array}{c}21 \text { months, } 3 \\
\text { months }\end{array}$ \\
\hline
\end{tabular}

In altitude movements, the same periods of 12 months and 70 days were identified. In the plane coordinates in the South-North direction, components with periods of 12 months and 3 months were identified. In plane coordinates in the West-East direction, the periodicals differ in duration, the duration ranges from 12 to 24 months, the component with a period of 3 months is the same for all stations.

The detected amplitudes of periodic movements of the stations averaged 7-10 $\mathrm{mm}$ in height in long periods and 3-6 $\mathrm{mm}$ in short ones, in the plane coordinates 1-2.5 $\mathrm{mm}$ in long periods and 1.5-3 $\mathrm{mm}$ in short ones.

In addition, the revealed trend showed a tendency for all stations to move to the northeast.

Table 2. Trend movements of stations in plane coordinates

\begin{tabular}{|c|c|c|c|c|c|}
\hline & GORN & KRON & KUP2 & LOM2 & SEST \\
\hline The station movements in the direction of S-N, cm. & 8,5 & 10,6 & 8,7 & 10,5 & 10,8 \\
\hline The station movements in the direction of W-E, cm. & 16,1 & 15,9 & 15,5 & 15,7 & 15,6 \\
\hline
\end{tabular}

A sketch-map was compiled in the QuantumGIS software, which clearly displays the location of stations, movements over 8 years in each of the directions and the general trend of movement. 


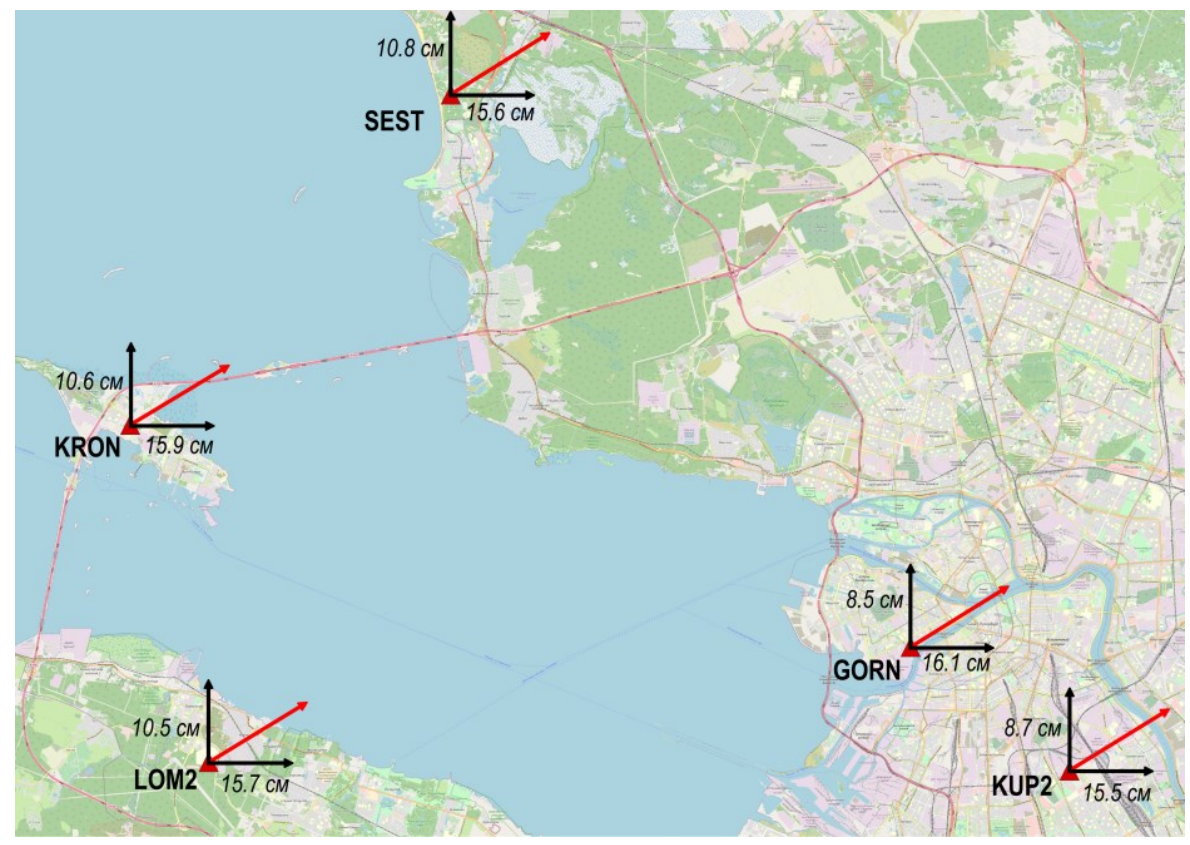

Fig. 10. The sketch-map of the location of the studied stations and their movements

The results obtained in this work are confirmed by previous studies in the Baltic region, according to which GNSS stations move in the direction of the northeast with an average speed from $19.9 \mathrm{~mm} /$ year in the north to $23.9 \mathrm{~mm} / \mathrm{year}$ in the south [6].

\section{Conclusions}

As a result of the study, changes in the position of GNSS reference stations were identified and analyzed. Periodic components and the main trend were identified. The "Caterpillar"-SSA method does not explain the reasons for the occurrence of periodicals. The interpretation of the movements of stations and their periodicals can be obtained by studying the totality of stations and each station separately.

The study of periods and trends, as well as their causes, is a very important task when conducting geodetic monitoring. These studies allow us to identify movements caused by natural processes and distinguish them from changes in the behavior of the trend that are caused by negative processes, as well as to prevent emergencies and improve the accuracy and reliability of measurements.

\section{References}

1. N. E. Golyandina, Metod "Gusenitsa»-SSA: analiz vremennykh ryadov [The "Caterpillar" method-SSA: time series analysis] (St. Petersburg State University, Saint-Petersburg, 2004)

2. D.L. Danilov, A.A. Zhigljavskij, Glavnye komponenty vremennykh ryadov: metod «Gusenitsa» [The main components of time series: the "Caterpillar" method] (Saint-Petersburg, 1997)

3. C. Xu, D.Yeu, Tectonophysics, 665, 118 (2015)

4. S.V Vohmjanin, Sibirskij ajerokosmicheskij zhurnal, 11, 59 (2010)

5. V.L Gorshkov, N.V Shherbakova, GeoScience, 4-2012, 12 (2012)

6. T.V.Guseva, I.S.Krupennikova, A.N.Mokrova, V.P.Perederin, N.K.Rozenberg, Geofizicheskie issledovaniya, 21, 24 (2020) 